\title{
NO PIENSO, LUEGO EXISTO. \\ UN RETO PARA LA NUEVA BUENA CIENCIA
}

\author{
I DO NOT THINK, THEREFORE I EXIST. \\ A CHALLENGE FOR GOOD NEW SCIENCE
}

\author{
Manuel AlmENDRO \\ Oxigeme*
}

A María Teresa Román In Memoriam

\begin{abstract}
Resumen: El adverbio «No» con el que se inicia el título de este artículo marca un proceso de cinco siglos. Es un «No» que resuelve la mente dual cartesiana en aras de una mente plena; un «mindfulness» que abre paso a la consciencia. El puente entre ciencia y consciencia aparece ya a niveles internacionales como el gran reto de nuestro tiempo, dada la situación de desestabilización que se incrementa a diario en nuestras sociedades. Es indiscutible que la ciencia y su tecnología han cambiado la faz del mundo, han permitido vías de comunicación fundamentales para entender que somos planeta, han generado el progreso, pero también un déficit ecológico preocupante. La ciencia ha sido capaz de modificar el mundo exterior material, pero se estrella ante la complejidad, la incertidumbre, y el caos que "regula» la mente y la consciencia, y además abre el campo íntimo de acceso al Ser. Las ciencias deterministas están siendo contestadas por los nuevos paradigmas científicos que proponen un acercamiento a una ciencia con consciencia. El aporte de Oriente y de las nuevas filosofías y psicologías -superando el férreo control de Laplace- auguran excelsas perspectivas para una posible «salvación».
\end{abstract}

\footnotetext{
* Manuel Almendro, director de Oxigeme: Centro para una Psicología de la Conciencia. E-mail: almen@oxigeme.com www.oxigeme.com
} 
Oriente y María Teresa llevan tiempo llamando a la puerta. En estas líneas se desarrollan algunas vías para poder construir entre todos ese maravilloso puente que puede constituir una buena nueva para la psicología, la filosofía, la medicina etc. Y se agradece a una profesora que con rigor académico haya sido capaz de remontar los escollos de una academia algo reticente a las aperturas.

Palabras Claves: Ciencia, Consciencia, entropía, Procesos Disipativos, Crisis Emergente, Meditación-Mindfulness

АвsтRAст: I do not think, therefore I am. The adverb "No" in the title of this writing highlights a process that dates back five centuries. It is a "No" that dissolves the Cartesian dual mindset for the sake of achieving a full mind, a "mindfulness" that opens the way to Consciousness. The bridge between science and consciousness is discussed at the international level as the great challenge of our time, given the destabilizing situation that we see increasing daily in our societies. Science and technology have indisputably changed the face of the world. They have established fundamental means of communication that help us realize we are actually a planet. They have generated progress, although at the cost of a worrying ecological deficit. Science has been able to modify the material outer world, but it crashes on the rocks of complexity, of uncertainty, and of the chaos that "governs" the mind and consciousness. While these may be obstacles to science, they nevertheless open the way to that inner realm that allows access to the Being. The deterministic sciences are being challenged by new scientific paradigms that propose a science to be approached with consciousness. Eastern cultures as well as new philosophies and psychologies lend contributions that overcome Laplace's iron grip and augur eminent perspectives toward possible "salvation". The Eastern world and María Teresa have been knocking on the door for some time. These lines expound on some of the ways that we can build together a wonderful bridge full of promise for psychology, philosophy and medicine, as well as other fields. What is more, we are grateful for a teacher whose academic rigor enabled her to overcome the pitfalls of an academy that is somewhat reluctant to open up.

Keywords: Science, Consciousness, entropy, Dissipative Processes, Emerging Crisis, Meditation-Mindfulness 
Quizás el título de este escrito simbolice el mejor regalo para María Teresa. Los nuevos paradigmas en la ciencia pretenden salir de una visión determinista de consumo anclada en concebir la realidad como materia mecánica rentable, también de concebir la vida como programación de conductas -aunque haya seres humanos empeñados en sus profecías autocumplidas-. Por todo ello estas palabras tratan de abrir paso a una ciencia de la esperanza que no se atasque en la miopía reduccionista. Revelación intuitiva y rebelión científica (Almendro, 2002, 2013; Almendro y Weber, 2012) abren un puente que integra Oriente y Occidente, sabiduría intemporal y ciencia moderna.

He sido testigo y de hecho sigo siendo eco de universidades californianas en donde este anhelo sigue presente. California, como sabemos, puntera en grandes descubrimientos de nuestra era ¡Qué mentes tan abiertas! (Walsh y Vaughan, 1993).

Algunos avezados hablan ya de abrir campo entre ciencia y espiritualidad; e incluso, de nuevos avances como neuroteología (Walsh, 2007). Desde luego no hay investigación que triunfe que no parezca demencial a primera vista. Y de la raza de esta apertura es María Teresa y de los que la han sabido respetar; y, por ello, abrir camino. Es deseable que se extienda a otros sectores académicos solidarios.

\section{Reflexiones Sobre la Ciencia}

Según la perspectiva histórica, a Descartes se le eleva o se le degrada con relación al mapa creado a partir de la separación mente-cuerpo, y al consiguiente dualismo. De igual forma a Newton por su visión mecánica del universo. De forma parecida a Darwin por la mecánica evolutiva de las especies que se tambalea ante los procesos de simultaneidad y discontinuidad. Sin embargo, una cosa es Descartes -el autor- y otra el cartesianismo; de igual forma se puede establecer para el newtonianismo y darwinismo, embargados por numerosos intereses industriales. $\mathrm{Al}$ menos en Descartes y Newton hay una "divinidad» que da consistencia al orden (Almendro, 2002, 2013). 
Perdida una consciencia rectora sobre la realidad, como una totalidad en sí misma, relegarla a materia despedazable ha supuesto graves consecuencias. Pinillos (1999) en su obra El corazón del laberinto, al parecer no demasiado comprendida por sus alumnos, es contundente: los Universales -que están más allá del dualismo- siguiendo la lógica antigua poseían una realidad objetiva que constituía la sustancia y la esencia de las cosas. Privado del soporte de los Universales, el orden del universo quedaba a disposición de quien lograra manipularlo. Esta observación marca una intuición preocupante. Son conceptos cercanos a las consecuencias expuestas por Pániker (1989) con respecto al alejamiento del «Origen». Nos encontramos así con que el dualismo estaría en la base de la división que afecta al pensamiento occidental, dualismo separatista mente/cuerpo, yo/el otro, etc., y que, siguiendo a Pinillos (1999), podemos objetar que este dualismo estará en la base de la separación de los rumbos: el del humanismo por una parte y el de la revolución cientifica por otra.

Si por una parte el cartesianismo ha ofrecido la posibilidad de análisis de la materia como método científico y llegar al átomo y a la física subatómica, la física teórica desde Newton realiza predicciones a partir de cálculos matemáticos sobre los cuerpos celestes y objetos materiales en general, con magnitudes como peso, masa, inercia, aceleración etc., cuya objetividad física es incuestionable. Ello hace que el lenguaje matemático sea eficiente por la comprobación empírica posterior. El avance se ha realizado desde lo más simple de la geometría euclidiana, un in crescendo desde el punto a la línea y de aquí al concepto de campo, avanzando desde la partícula al fotón, aumentando en complejidad en teorías como la relatividad, conceptos como el vacio, la curvatura del espacio, y las leyes gravitacionales que pueden darse entre los cuerpos celestes. Es evidente que, a partir de conocer las coordenadas de un cuerpo, se ha podido predecir matemáticamente las leyes que gobiernan todo su contexto. Está claro que existe un comportamiento de sistema en la Naturaleza.

La complejidad de la teoría cuántica se sumaría a este proceso de tratar de establecer el fundamento de la realidad. Pero esta ciencia que ha cambiado al mundo tiene graves escollos para conocer el interior humano, fundamentalmente la mente y aún más la consciencia, que por su carácter abierto e hiper-complejo se escapa a las predicciones y a las programaciones. El maquinismo no da explicaciones sobre la esencia existencial. 


\section{La ciencia es ciencia y sus consecuencias}

¿Qué veo desde mi ventana? "Consideraba, primero, que tenía una cara, manos, brazos y toda esta máquina compuesta de huesos y carne, como se ve en un cadáver, la cual designaba con el nombre de cuerpo". "¿Qué es lo que veo desde mi ventana? Sombreros y capas, que muy bien podrían ocultar unas máquinas artificiales, movidas por resortes» (Descartes, 1993: 135, 141). Frases representativas del modelo filosófico cartesiano.

Ha habido consecuencias. Los modelos biológicos han seguido los modelos de la física reduccionista considerando al cuerpo como una colección de células alineadas de forma casual. Es la historia de la Biología (Jahn y Lother, 1989). La Biología, que ha obtenido grandes avances en el campo genético, no ha mucho tiempo, se ha visto envuelta en los aspectos eugenésicos y afortunadamente en contundentes reacciones desde la ética humanista. Hay críticas que consideran a Richard Dawkins (1976), por cierto, creador de la hipótesis del «gen egoísta», como ultra reduccionista en plena actualidad.

Y de la biología -vía Paulov- al modelo de la psicología, a la máquina E-R seguidora de los principios de Newton y sus consecuencias que se explican en este escrito, en el que además está presente la idea de pasar de la caja negra a la caja translúcida.

\section{La ciencia abierta responde}

Bertalanffy L.V. (1992) realiza una de las críticas más contundentes al conductismo y a sus consecuencias socioculturales que serían inexplicables de no tener en cuenta al imparable medio industrial norteamericano. También la crítica está presente en otro físico y pensador de talla como Erwin Schrödinger (1997), premio Nobel y hombre de vasta cultura -rara avis hoy en día- que puede hablar tanto de Lamarck como de Huxley, de Ortega o Unamuno, y que niega la capacidad de la Física y Química para explicar el organismo vivo; y, además, duda de la felicidad técnica de la humanidad (Schrödinger, 1998). 
Davies (1988, 1992; Davies y Gregersen, 2010) critica la línea reduccionista ya que ésta niega los fenómenos emergentes y además supedita todo a los procesos físicos fundamentales: es decir, a un simple juego de átomos que interactúan al azar. Crítica que encuadra con fina ironía, afirmando que «es evidente que es mucho más sencillo estudiar un perro como si fuera una colección de células o de átomos interactuando de forma compleja que como un perro» (Davies, 1992: 185). «[...] La mayoría de los biólogos modernos son firmemente mecanicistas o reduccionistas en sus apreciaciones. En la actualidad se considera frecuentemente a los organismos vivos como máquinas complejas programadas a nivel molecular» (Davies, 1992: 21). Y que "los biólogos reduccionistas se atrincheran en la identificación de los mecanismos con base física que operan en el organismo para asegurar que la vida "no son más que" procesos físicos ordinarios [...] las grandes lagunas en el conocimiento sólo son atribuibles a las limitaciones técnicas» (Davies, 1992: 137).

Precisamente Ortega (1997, a, b, c, d), admirador de C.G. Jung al referirse a la Psicología superlativamente empírica, avisa incisivamente de que no pierda el sustantivo por el amor del adjetivo. Peat (1988), en la obra de síntesis -Sincronicidad- entre la Física y la Psicología y en la línea de Davies nos expone que «[...] el análisis con su reducción de la complejidad a la simplicidad es tradicionalmente un modo útil de practicar la ciencia. No obstante, sus desventajas se hacen aparentes cuando el análisis adopta la posición del "nada más". Cuando la química es "nada más que la física de las moléculas", un organismo es "nada más que su química constituyente" y la mente "nada más que células nerviosas y neuroquímicas en acción", el resultado es la estrechez de perspectiva» (Peat, 1988: 77). Por ejemplo, para Laughlin y Rock (2013), en su intento de aproximarse a los rigores de los métodos científicos practicados en las llamadas ciencias duras, la psicología a menudo produce un cientificismo ingenuo en la construcción de la teoría y la investigación empírica. Ese «nada más» simbólicamente lleva consigo todo el determinismo y reduccionismo de la exclusividad lineal. El extremo a que había llegado la causalidad estaría señalado en Laín (1999) al explicar a Zubiri, sobre la reducción conceptual que habría llevado a la ciencia moderna a confundir la «causalidad» con la «ley». Además, Zubiri profundiza en algo que se alinea con el concepto de Prigogine (Prigogine y Stengers, 1984) y Lorenz (1995) relativos a la «no predicción de probabilidades» y a la «dependencia sensible» ya que las estructuras celulares producen la psique por otra diferencia: la elevación. El brotar desde, en Zubiri -según Laín (1999)- «consiste en elevación, en el hecho de que la realidad naturada se eleve a un modo de ser real cualitativamente nuevo y superior» (Laín, 1999: 66). Una elevación que llega a la evolución como 
potencial radical del cosmos, de "hacerle hacer a la materia lo que de si misma no podría hacer: la hominización» (Laín, 1999: 67). Estamos aquí frente a lo inefable. Son teorías que ofrecen un orden evolutivo para explicar la existencia del mundo frente a la realidad reducida a trayectoria, sabiendo que esto último nos llevará a la segunda ley de la termodinámica y al concepto de entropía, objeto de adhesiones y críticas que van a definir dos modelos de ciencia, que se pueden resumir de forma sencilla en determinista y no determinista (Almendro, 2002, 2013). Desde este punto de vista es lógico que nos encontremos a filósofos como Ortega, Aranguren, que hablen de la barbarie y la incultura en nuestra sociedad científica.

Pero la buena ciencia apunta más arriba y no cesa en su empeño, aunque sea a través de las revoluciones científicas y la revolución metodológica en que el propio proceso evolutivo marca el camino de forma inexorable: tiene que morir un paradigma para que otro nazca (Kuhn, 1975; Feyerabend, 1975). La teoría de la relatividad, las teorías del caos, la teoría de cuerdas etc., han sobrepasado con creces la mecánica clásica al encarar retos como la naturaleza de la luz, las partículas subatómicas, el vacío, e incluso la electricidad. El fin de la ciencia-es comúnmente aceptado- se producirá por a) dedicarse a los intereses comerciales, b) por alcanzar un mundo feliz, c) o por el choque con una realidad que escapa a la prueba de la verificación. Hay quien encara la realidad oficial bajo la que emerge una realidad oculta: el hinduismo subterráneo de occidente (Pániker, 1989); y la limitación que padece la racionalidad para entender lo sagrado (Pániker, 2016). Todo esto acelera felizmente el proceso hacia la explosión de la complejidad y la incertidumbre.

D’Espagnat (1995) pone el dedo en la llaga, y propone un reto difícil de entender, cuando critica que los físicos mantengan que pueden describir la realidad tal como realmente es. De tal forma afirma, que cuando todo es dicho y hecho, el nivel de credibilidad es bajo. D'Espagnat está postulando una realidad externa, que pueda ser inteligible e independiente, aunque la plantea fuera de un idealismo radical o de un objetivismo radical. Para validar el realismo abierto D'Espagnat propone que existe algo cuya existencia no procede de la mente humana. Ese algo existe fuera de nosotros, lo cual significa que esa realidad independiente es independiente de nosotros mismos. Para ello, D'Espagnat hace un repaso a científicos y filósofos, siendo David Bohm (1988) -y su orden implicado- el físico que nos parece más cercano a estos postulados. Entiendo que la afirmación de D’Espagnat proviene probablemente de una intuición. Es 
sabido que la respuesta de Einstein sobre cómo había llegado a semejantes conclusiones en sus teorías sobre óptica o la relatividad era, "ya lo sabía desde antes».

\section{Graves consecuencias a tener en cuenta}

La ciencia se puede convertir en cultura y, con relación a ello, puede que la idea newtoniana de cuerpos rígidos celestes en un mundo fijo de materia y espacio se pueda transvasar a cuerpos rígidos humanos a partir de establecer una realidad acondicionada a un tiempo histórico-cultural determinado. Sobre la primera ley en la que un cuerpo en movimiento o en reposo estaría condenado a permanecer siempre en cualquiera de los estados, inferimos según esta ley, que ese cuerpo no posee ningún tipo de categoría, fuerza y capacidad, para modificarse a sí mismo. Es un cuerpo que corresponde a la caja negra, metáfora que representa al individuo en el conductismo psicológico. Si partiendo de la segunda ley, en que un cuerpo para que cambie su situación ha de ser a través de la acción de otro cuerpo, podemos inferir que un cuerpo sólo podrá modificar su situación mediante la acción de otro cuerpo. De esta forma inferimos que no sólo no se carece de posibilidades internas, sino que se genera una dependencia a un mundo de otros cuerpos-prótesis. A esta segunda ley le correspondería la acción del reflejo condicionado del conductismo clásico y el refuerzo del conductismo operante. La tercera ley, de acción reacción, creo que esconde todo el principio de contradicción y de separación del par de opuestos (Almendro, 2002, 2013).

Y ha sido desde las teorías del caos desde donde se ha invertido la segunda ley de la termodinámica, estableciéndose la superación de la muerte térmica de los sistemas por una evolución disipativa (Prigogine y Stengers, 1984, 1994). Y este principio unido a otras aperturas hacia la complejidad ha abierto nuevos caminos en psicología y psicoterapia (Almendro, 2002, 2013; Almendro y Weber, 2012).

Es nuestro propósito estar fuera de la oscuridad esotérica de consumo a partir de la frase de Albert Einstein «en un profundo sentimiento de la existencia de una mente superior que se revela en el mundo de la experiencia arraiga mi concepción de Dios» (Einstein, 1980: 34). 


\section{Dos aspectos han bifurcado en la ciencia}

Desde el principio - ante el caos reconocido ya por Hesíodo-, se ha intentado controlar la realidad y predecirla, bien por augurios o por programaciones científicas. Sin embargo, da la impresión de que la realidad se rebela entre carcajadas sardónicas. No hay más que ver un telediario.

$1^{\circ}$. Proceso de diferenciación. La realidad se escapa al control humano, es cuestión de observar la historia. A partir de este proceso, la visión evolutiva se alinea a «la fuerza de la diferenciación» de Spencer (1855) y se manifiesta en el devenir de los sistemas vivos y abiertos en los que se daría una ilimitación de características difícilmente catalogables.

La clave de lo vivo -en un comienzo- parece estar en poder explicar el proceso de evolución, su qué y por qué; algo que de una forma concreta y actualizada se pretende a través de este "principio de diferenciación» que Prigogine (Prigogine y Stengers, 1984, 1994) retoma y que se establece como uno de los "principios diferenciales de la variabilidad» (Juan-Espinosa, 1997), en el que se sostendría que los organismos parten de una relativa indiferenciación y globalidad y se encaminan hacia una progresiva diferenciación. Otra cuestión es encerrarlo en una actividad causalista.

Justo es también detenernos en esa visión de una materia dinámica. Ya Leibniz concebía a la materia como fuerza, en una perspectiva que supera la visión mecánica del universo. Pero si además seguimos a Laín (1999) en el libro ¿Qué es el hombre?, nos encontramos con que ya en Zubiri había una visión dinamicista, científica y filosófica de la realidad del cosmos, bajo la concreción de un mundo que es dinamismo. Por lo tanto, como algo constitutivo del mundo.

Así que, más que establecer una máquina simple, lo que se plantea es una realidad inagotable compleja e infinita bajo la que emergen procesos no lineales abiertos a la turbulencia. Es el «orden del caos». Las ciencias del caos ofrecen métodos para ver orden y pauta en lo que representa desorden para las estructuras deterministas. Ese método, ya lo hemos expresado, se refleja en el concepto de estructuras disipativas (Prigogine y Stengers 1984, 1994), en la teoría de «los fractales» de Mandelbrot (1988); o a niveles más divulgativos y anímicos, en las 
siete leyes del caos de Brigg y Peat (1999). Por lo tanto, estamos hablando de que existiría un desorden impredecible que a su vez posibilitaría la existencia de un orden bajo el desorden turbulento, que surge precisamente de lo relegado al azar o al ruido de fondo, y a partir de que el caos contempla el sentido de totalidad de la realidad. La entropía aquí no es vista como desgaste, sino que se le da la vuelta y se presenta ya como fuente de creación continua de nuevas realidades (negantropia).

$2^{\circ}$ Entropía y disipación. La visión determinista parte de la entropía como la degradación progresiva por pérdida de energía que habría de terminar en la muerte térmica y la desintegración del universo. Son consecuencias inevitables si sometemos la realidad al orden determinista laplaciano, que parte de unas condiciones absolutas iniciales que fijan una trayectoria mecánica y predeterminan la realidad implicando trayectoria, rígida regularidad, y predictibilidad. Es el orden determinista de las contingencias de Skinner (1987, 1971); y el orden de las computadoras de Marr y Newell, según el análisis de Monserrat (1995, a, b).

Frente a ello y a ese modelo de realidad psicológica que se deriva del reduccionismo científico hay quien desde la propia ciencia reivindica el mundo interior. Francisco Varela, se decanta por esta perspectiva a partir de criticar el divorcio de la ciencia clásica con la experiencia cotidiana. Y es que el ser vivo tiene experiencias íntimas; e implica, por ello, posibilidades de transformación a través de la experiencia, por ejemplo, cambiando sus conexiones neuronales a través de la vivencia cotidiana. Varela (1990): « [...] la inteligencia más profunda y fundamental es la del bebé que puede adquirir el lenguaje a partir de manifestaciones diarias y dispersas» (Varela, 1990: 56). Además, siguiendo a Varela (1990), todo esto comporta un conocer inseparable de nuestro cuerpo, nuestro lenguaje y nuestra historia social, concibiendo además la corporalidad como necesaria; es decir, nuestros cuerpos no solo como estructuras físicas sino como estructuras vividas y experienciales (Varela et al., 1992). Y concibiendo a lo vivo como lo enactivo, es decir, como capaz de hacer emerger un mundo (Maturana y Varela, 1984). Por lo tanto, la complejidad del «ser vivo» supone poseer inteligencia propia para salirse del carril predeterminado sin someterse a la utopía del control de laboratorio ejercido sobre un gen en una naturaleza incontrolable.

Por lo tanto, podemos ver que en el caos nos encontramos ya ante una ciencia humana: un gran desafío en el que el valor de lo psíquico adquiere singular relevancia. Un desafío ante lo que representa la degradación creciente de los conceptos entrópicos clásicos. La «no linealidad» conlleva en sí una continua 
«ruptura de simetrías» propia de los sistemas abiertos, siendo un fenómeno que permite la emergencia de los subórdenes de los cuales estamos hablando. Pero si importante es la «no linealidad», lógicamente "la complejidad» que todo ello conlleva es también un concepto clave. La complejidad es de por sí tan contingente que aparece casi como indefinible. De hecho, Prigogine y Stengers (1984, 1994) afirman que lo importante ante los sistemas complejos es nuestra limitada capacidad para comprenderlos. La complejidad, casi anecdóticamente, implicaría establecer la relación existente entre el ácido sulfúrico, el vuelo de las águilas y una sinfonía de Mozart. Creemos que la "complejidad» como síntesis sería una característica inherente a las «ciencias de la totalidad» que parten de la realidad como un proceso emergente, múltiple y diverso; y que además incorpora lo trans-disciplinar, lo transcultural, abordando el mundo de lo objetivo y de lo subjetivo, de lo singular y de lo plural, de lo finito y de lo infinito, de las certezas y de las incertidumbres, de lo establecido como verdad y de lo abierto a nuevos planteamientos del conocimiento. Sirva como ejemplo de «complejidad» el poder medir la rugosidad de la costa o de un mosaico, a partir de los fractales de Mandelbrot (1988), o abordar «la complejidad» de la manifestación psicológica. Esa complejidad necesita ser concebida, investigada, explicada, narrada, descrita, percibida; en fin, conocida de tal forma que nos permita abordar el sentido de totalidad de la realidad y nos vacune frente a una excesiva especialización que atomiza y actúa a la postre en contra de todo lo que esté fuera de su ámbito privado. La realidad, a partir de estas concepciones, no podría concebirse como rellena de partes desconectadas. Según esta "complejidad», los sistemas, a su vez complejos, contendrían un orden subyacente y los sistemas simples podrían producir comportamientos complejos (Almendro, 2002, 2013).

\section{Otras vías en psicología}

\subsection{Las crisis evolutivas y los procesos de investigación}

Precisamente, adelantamos ya que, en relación con esta inquietud, nuestra perspectiva de una psicoterapia del caos se encuadra en lo que -como una posible integración del proceso sintomático- hemos denominado "Crisis Emergente», fenómeno que tendría cierta relación con los diagnósticos de forma genérica etiquetados como crisis de pánico, crisis reactivas, crisis transitorias de diverso calado, o sea, crisis en general, etc. Crisis que podemos perfectamente trasladar a fenómenos sociales, ya sean erupciones violentas de diversa índole, movimientos 
económicos como los bursátiles, así como fenómenos atmosféricos, etc. En Psicología, pues, la Crisis Emergente (Cr. E.) admitiría que «lo patológico» irrumpe desajustando «la normalidad» del individuo con la posibilidad de proporcionar nuevas reestructuraciones de cara a crear un mejor acoplamiento con el entorno. Desde el punto de vista del sujeto entendemos de forma general que las Crisis Emergentes tienen que ver con un suceso vital en los que aparece, brota, una sintomatización súbita, mutación inesperada, caótica y urgente, que rompe los referentes del individuo consigo mismo y con su entorno, produciendo la llamada patología, algo que para nosotros correspondería, como Crisis Emergente, más a una ruptura/oportunidad re-organizativa del paciente que a una patología degradante, ya que esa emergencia «no lineal» formaría parte de un proceso de renovación y de creación de diferencias vitales y naturales en la constitución del ser humano como individuo.

Al principio spenceriano nosotros añadimos el de la «positivación de lo patológico», cuya metodología puede explicarse de forma sencilla como aquella que puede transformar el obstáculo en palanca; es decir: ser efectiva empíricamente. Bajo este supuesto, el síntoma como punto de atracción se despatologiza; la ruptura agitadora, productora de inestabilidad y de gravedad, no es degradada, ya que se considera que va a permitir diferencia y posibilidad de curación al dar paso a la emergencia de nuevos órdenes vitales para la estabilidad general del paciente. Bajo el criterio de la "positivación de lo patológico» el síntoma es mensajero de una normalidad precaria y caduca para el individuo que necesita renovación a pesar de su posible espectacularidad, y representa así mismo una complejidad que encuentra significación en la coherencia más allá del punto máximo de la agitación psicosomática, en el hallazgo por parte del paciente de una «autoorganización» y de nuevos acoplamientos con el entorno. No podemos cortar la cabeza al mensajero. El síntoma, pues, como una puerta abierta a la transformación vital. Es lo que conceptualizamos como Crisis Emergente (Almendro 2002, 2013, Almendro y Weber, 2012).

Profundizando en un nuevo modelo empírico en expansión, entendemos que la díada primera/tercera persona en el proceso investigativo sobre la consciencia es de vital importancia. El nivel de implicación del investigador en la experiencia meditativa a partir de observarse en primera persona se establece como proceso previo para ser observador en tercera persona. La sutileza de esta experiencia la pone de manifiesto el profesor José María Prieto (2007) en la identificación entre psique y el chi (energía) de la antigua china, sutileza que se amplía cuando afirma que con la meditación la psique vuelve a casa. Cabe recalcar que en nuestras 
investigaciones destacamos el valor de integrar la perspectiva primeraltercera persona, tal como propugna el enfoque neuro-fenomenológico. En esta línea, en una investigación reciente (López-Suárez, 2016; Almendro; López-Suárez, 2017), utilizando la técnica de Respiración Ventral (RV) y el enfoque neurofenomenológico, se estudian los correlatos neuroeléctricos (utilizando técnicas de EEG) con importantes conclusiones.

Investigaciones pioneras sobre modelos y sustancias provenientes de la Medicinas Tradicionales Indígenas (MTI) detallan lo poco que sabemos del cerebro. Partiendo de investigaciones con técnicas de neuroimagen, se pone de manifiesto que a partir de determinadas experiencias con sustancias se altera de forma transitoria la estructuración jerárquica neuronal y con ello el diálogo que se establece entre las distintas áreas. Los denominados modelos de inferencia Bayesianos postulan que la experiencia subjetiva de la realidad emerge de la interacción dinámica entre la información sensorial entrante y la interpretación que hacemos de dichas señales, interpretación que hacemos basándonos en nuestro conocimiento previo y en nuestras expectativas. En este marco teórico, la corteza frontal se encontraría en el punto más elevado de la jerarquía y modularía la información entrante de acuerdo con una serie de a prioris. Cuando el control ejercido desde arriba se relaja y la excitabilidad en niveles corticales inferiores aumenta, es posible que una actividad débil apenas perceptible en condiciones normales ahora sea capaz de alcanzar niveles superiores y ser percibida. Una mayor excitabilidad en las áreas visuales, auditivas o de memoria, sería responsable de los fenómenos perceptivos y de acceso a información almacenada en el recuerdo. Esta mayor excitabilidad general, combinada con la disminución del control férreo que ejercen las regiones frontales sobre los procesos cognitivos, explicaría la naturaleza abrumadora que pueden tener en ocasiones estas experiencias. Aun produciéndose siempre estos dos efectos, mayor excitabilidad neuronal y menor control frontal, los efectos vendrían modulados por factores totalmente individuales como la personalidad, el estado de ánimo, las expectativas y las experiencias previas con estas sustancias (Riba, 2016).

Sin embargo, establecemos una primera reflexión en el posible encuentro entre el conocimiento indígena y la ciencia. Como hemos visto, las técnicas de neuroimagen revelan que la ayahuasca produce una modificación de la transferencia de información entre áreas neuronales y consecuentemente una alteración del control jerárquico (Riba, 2016). Podemos entrever una correspondencia entre esta alteración de patrones neuronales ya consolidados en el individuo con la irrupción de un caos emergente producido por la experiencia psicológica, con 
posible curación de memorias ancestrales (aporte de la medicina indígena). Dando quizás la posibilidad de un posible proceso evolutivo digno de investigar. Es obvio que todas estas investigaciones extremadamente delicadas están en sus comienzos y se necesita una prudencia infinita a la hora de establecer resultados.

Hemos de añadir que la segunda reflexión muestra la preocupación por los posibles conflictos derivados de intereses económicos, de estatus personal e incluso político-sociales, aunque destacando sus potenciales aplicaciones en el campo de la clínica y de la salud en general. Desde esta perspectiva planteamos que es necesario un acercamiento riguroso al complejo mundo de las MTI. Y lo afirmamos a partir de algunas mediciones sobre estos procesos. Por ejemplo, en el VEEC - VEEC (Validación de Experiencias en Estados de Consciencia) de 36 ítems en escala likert de 5 puntos (diseñado por Manuel Almendro en 2015 y actualmente en proceso de validación), hemos encontrado que la variable de bienestar psicológico de Ryff correlaciona positivamente con la sub-escala cognitiva del inventario de expresiones sobre espiritualidad ESI (.700) y con la variable de conexión corporal de la escala de conexión corporal SBC (.694); pero negativamente con la evaluación de síntomas del SA-45 (-.646) y con la dimensión de desconexión corporal de la escala de conexión corporal SBC (-.661). La dimensión de conexión corporal de la escala de conexión corporal SBC correlaciona positivamente con la subescala cognitiva del inventario de expresiones sobre espiritualidad ESI (.773), con la escala de bienestar psicológico de Ryff (0.694) y negativamente con la dimensión de desconexión corporal de la escala de conexión corporal SBC (-.781). La dimensión de desconexión corporal de la escala de conexión corporal SBC, correlaciona negativamente con la subescala cognitiva del inventario de expresiones sobre espiritualidad ESI (-.656). El cuestionario de validación de experiencias en estados de consciencia VEEC, correlaciona positivamente con la subescala cognitiva del inventario de expresiones sobre espiritualidad ESI (.803) y con la dimensión de conexión corporal de la escala de conexión corporal SBC (.731) y correlaciona negativamente con la dimensión de desconexión corporal de la escala de conexión corporal SBC (-.543), etc. (López-Suárez, 2016; Almendro, López Suárez, 2016; Almendro y López-Suárez, 2017; Almendro, López-Suárez, Horrillo, en prensa).

El VEEC, con una puntuación de alfa Cronbach -sobre 84 sujetos- de 0.97 nos ofrece que puede constituirse en un buen instrumento para contribuir a medir los estados expandidos de consciencia, sabiendo que estos estados se resisten a ello debido a su sutil naturaleza. Aunque es necesario contar con una muestra mayor de sujetos, y este es actualmente nuestro propósito. 


\section{Ciencia y Consciencia}

Quizás la frase de que cuando la psicología trata de alcanzar la consciencia, es cuando comienza el camino de regreso a casa, represente el nuevo reto necesario para ampliar nuestro concepto de realidad, al que se uniría la apertura de la consciencia

Queda establecido que los procedimientos de la mente se inician con una mente primaria, simplista, mecánica y automática, establecida a veces por la economía de la acción y otras por las programaciones propias o ajenas. Una mente secundaria que ya puede establecer de forma consciente la relación causa efecto, y hay quien establece que esto es todo. Pero ya Freud con el inconsciente, no digamos el inconsciente arcaico, la vivencia oceánica y a partir de aquí de otros investigadores ponderados por María Teresa como Jung y el inconsciente colectivo, Assagioli y la supraconsciencia, se comienza a escribir otra historia en la ciencia occidental: estableciéndose que más allá de una mente pensante hay una actividad mucho más profunda y posiblemente un nuevo paso evolutivo de nivel supra-racional, que aún no entendemos muy bien. Y es que esa Supra-consciencia o CONSCIENCIA es posiblemente continente y nosotros su contenido. La intuición y la sincronicidad de vivir la totalidad en la parte tendrían aquí un principio complejo de investigación que necesitaría de vivencia en primera persona.

Los grandes descubrimientos en la ciencia que dejan atrás al modelo newtoniano entran en el vértigo de materia y luz, corpúsculo y fotón. Erwin Schrödinger explica que la ruptura del vacío hace aparecer a la materia (Schrödinger, 1998, 1999). Y Popper (1994: 79, 69, 78, 34) sentencia que «[...] la física clásica no es capaz de dar razón en el sentido más fuerte [...]»; es decir, capaz de dar razón a la hora de precisar las condiciones iniciales que exige el determinismo. Por lo que propone una ciencia abierta, en línea con las ideas de autores tan relevantes como Prigogine, Varela, etc.

La Física es considerada como la madre de la ciencia, ya que se apoya en sus descubrimientos. Y es cierto que la Física está abriendo grandes campos y enormes desconciertos ante la naturaleza insondable de la realidad, tanto en lo infinitamente pequeńo: campos subatómicos, como en lo infinitamente grande: el infinito cósmico. Por lo tanto, hay un proceso evolutivo en lo que llamaría 
la buena ciencia, la ciencia que asume la complejidad de los sistemas vivos y abiertos.

Con respecto a la Psicología y al campo cerebral -el puente mente-cerebrose abren correspondencias insospechadas que tienen en cuenta la vivencia y sus reflejos con técnicas de neuro-imagen. Pero hemos de replantearnos ciertos postulados. Si ya Cronbach (1975) fue irónico sobre la felicidad producida por los tranquilizantes proponiendo la apertura correlacional, la crítica incisiva vino de Mandell (1985), denunciando el fallo del modelo biológico a partir del modelo del ser humano como máquina simple. Pero lo que interesa de este investigador es que ha sido uno de los pioneros en entrar en el campo de la neurobiología de lo numinoso. También Rubia-Vila (2006), manteniendo distancia, se hace eco de ello. Estamos ya ante una ciencia que aborda los sistemas vivos, complejos y abiertos a la incertidumbre, cuyas investigaciones proponen la curación en psicología como un proceso de auto-reorganización. Concretando en ello, en el proceso mencionado de crisis emergente, en nuestra escuela lo desarrollamos dentro de un marco amplio de terapia y formación en psicología y psicoterapia. No cabe decir que el abordaje de una ciencia de la Consciencia sea la clave.

Y desde la física de Einstein (1980), Bohm (1987) y el orden implicado, los ya mencionados D'Espagnat (1995), Heisenberg (1949) y su principio de indeterminación que nos libra de la soberbia, en correlación con los indecidibles de Gödel (1986), Kuhn (1975), Feyerabend (1975) y Sheldrake (1989) con los campos morfogenéticos, y así como un largo etc., han marcado un camino que a fecha de hoy sigue en el asombro ante una realidad que se escapa al control e incluso a la comprensión en sus máximas dimensiones. Muchos de estos investigadores han sido agasajados por María Teresa. 


\section{El Centro Rector}

Y en este apartado cabe detenernos en lo que podría constituir un punto fuerte que lo denomino centro rector, al que cada individuo habría de acceder en su proceso personal, ya sea psicológico, e incluso, filosófico y existencial. Este centro rector estaría constituido por la identidad personal, independiente e intransferible, y permitiría al individuo una conexión con su consciencia personal/universal para no convertirse en un recorte de las contingencias y no ser víctima de su propio poder anulador en el proceso evolutivo personal. Nadie puede alimentarse ni morirse por otro, de la misma manera que nadie puede acceder a este centro rector por otra persona. No cabe duda de que este cometido ha de llevar consigo un enlace entre la ciencia y la consciencia. La sabiduría intemporal, oriental, por deferencia a nuestra autora, nos dice que hay una "consciencia universal» y que el ser humano la lleva consigo en su cuerpo de forma individualizada. Y que esa «iluminación» de la que hablan los orientales consistiría en unir esa consciencia individualizada con la «consciencia universal» y total. Pero se interpone la sombra, la ignorancia (adviya), según los sutras de Patanjali. Y aquí la Psicología con su ciencia podría realizar un buen trabajo al investigar la naturaleza de esa sombra/ignorancia, conocer su constitución; es decir, su diagnóstico y su clínica. Se trataría, pues, de conocer la "patología» que se interpone entre esa consciencia universal con la consciencia particular, que aguarda en la materia, según Aurobindo (1997) y, por lo tanto, en el propio cuerpo. Esta es nuestra línea de trabajo e investigación en el Proceso Oxigeme ${ }^{\mathrm{TM}}$, muy lejos de una psicoterapia de cabotaje; es decir, hacia una psicología y psicoterapia de integración propia del siglo XXI.

\section{Ante la Puerta de la Consciencia}

El sol sale por Oriente y María Teresa se ha orientado toda su vida por saber acerca de este levante. Y sabemos que estuvo muy interesada por el budismo tibetano, el hinduismo y, en general, por todo el saber proveniente de esas latitudes que nutren sus raíces en el conocimiento olvidado, oculto, desoído, espiritual; en fin, un vórtice excelso alrededor de la Consciencia. Su labor pedagógica, libros y programas de televisión, dan cuenta de ello. Entrevistas suculentas a destacados profesionales, profesores de universidad, editores, psicólogos, filósofos, etc., tocando todos los temas en las mañanas de la TVE 2, a horas luminosas; es decir, de baja audiencia, pero con miles de seguidores en TV, e Internet y a través del Canal UNED. 
Para poder entrar en una psicología de la consciencia quizás tengamos que poner atención en la vivencia anómala desechada por la ciencia y que en cierto sentido puede que tenga que ver con no integrar niveles pre-cedentes y postcedentes. Y que además enfrenta la consciencia racional a la irracional en los griegos (Dodds, 1980; Gebser, 2011). Dodds (1980) trata de recuperar lo irracional y afirma que no sabemos nada sobre los misterios órficos y menos sobre la bendición divina de la locura de Sócrates; tampoco de la incubación de los sueños en los olvidados templos dedicados a Asclepios. Pocas veces, dice Dodds, se vertieron tantos niños con tan poca agua de baño (Dodds, 1980).

Lo desechado como no apto rompe el orden lineal siguiendo las leyes del caos. La consciencia emerge, esperando el momento propicio, dentro de los sistemas no ordinarios y probablemente no-lineales. Un hecho anómalo que está pidiendo paso, una vez discutido y acotado el espacio de la razón excluyente (Cardeña et al., 2010). La psicología que se acerca a investigar sobre la consciencia, añaden Krippner y Achterberg (2000), lo hace a través de poner en evidencia la vivencia anómala que ha sido destituida en el acontecer científico. Recuperar la luz de los antiguos parece ser el mandamiento. Otros autores claves señalan, como en el caso de James $(2002,1956)$, la necesidad de abrir campo a las diversas formas de la experiencia religiosa y a la investigación sobre la existencia de la consciencia. Abundan buenos trabajos sobre ello como los de Chalmers (1999) y Hunt $(2006,2007)$. También se suma a esta inquietud Edgar Morin (1974, 2011), poniendo de manifiesto el paraíso olvidado, reclamando la urgencia de una nueva vía abierta a la Consciencia. Y este anhelo de acceder a la integración, a lo Último, hunde sus raíces en la historia de la consciencia universal.

La puerta a este reto se abre especialmente a través del ya mencionado Jean Gebser, investigador altamente apreciado por María Teresa y sobre el cual compartimos y ahondamos en nuestros encuentros. Gebser (2011) se abre a lo insondable, al entendimiento de la evolución de la consciencia como clave de la vida. Su aportación supone una valiosa ayuda para poder comprender en qué nivel evolutivo de la realidad nos encontramos a partir de integrar los niveles evolutivos precedentes. Por lo tanto, este cometido nos lleva también a recapitular estos niveles de evolución (Gebser, 2011). Este vertiginoso proceso supone entrar en las profundidades platónicas y en la vida como oportunidad. Platón (1954), en sus cartas, advierte sobre dilapidar la vida en los excesos del placer que impedirá la escucha de las sagradas doctrinas, por eso Platón pasa al subconsciente de la cultura occidental. Una cultura dominada por la explotación del medio vital y cuyas consecuencias -según algunos- presagian el abismo. 
Y por todo esto, desde la nueva psicología, se reclama ya la despatologización de estas experiencias extraordinarias, y por ello de las emergencias espirituales, bajo el respeto al fenómeno que demuestra la verdad subjetiva (Cardeña et al., 2014). Recordemos que el término psico-espiritual y el psico-religioso está reconocido en el DSM IV gracias a mi apreciado colega David Lukoff.

Estos investigadores denuncian que este fenómeno no se ha estudiado en la población sana, reclamando que James (2002) ya lo propuso a principios del siglo XX. El desafío llega cuando personalidades de la talla de Stanley Krippner y Jeanne Achterberg, q.e.p.d., desafían con un «Both authors of this chapter have experienced anomalous healing experiences [...]». Ambos autores de este capítulo han experimentado experiencias anómalas curativas, citando que la clave parece estar en no desarrollar un fuerte intelecto en contra del Gran Poder (Krippner y Achterberg, 2000: 273).

\section{Un primer reto}

Podría consistir en salir del laberinto mecánico, cuyos efectos nocivos estarían detrás de la destrucción del ecosistema según Lovelock y su famosa hipótesis Gaia así como los movimientos de ecología profunda. Un cambio que debería de estar precedido por alcanzar el timonel de la consciencia, un cambio vivido y una consiguiente masa crítica que posibilite consenso aceptado socialmente. Si este salto de consciencia no se produce por una integración vivencial es entendible que el proceso de cambio se devalúe, se niegue, bajo incluso una ciega ironía, utilizando postulados de un cientifismo que pretende erigirse en religión; y que no sabe o no desea saber sobre las consecuencias de sus acciones en la destrucción ecológica.

Y en esta línea, crítica y expansiva, la contribución de María Teresa acercándonos a las sabidurías intemporales -liberadas de algunas creencias obsoletas- nos anima a seguir investigando en el maridaje de ciencia y consciencia. Y en ello andamos, tras luchas empíricas, sabiendo que la materia no es en absoluto inerte sino materia viva e inteligente. Y que gracias a la materia tenemos el mundo.

Y en esta avenida de la consciencia como aventura son agasajados por María Teresa personajes de la talla de Sri Aurobindo, propulsor de transformaciones 
desde la evolución de la materia; Jiddu Krishnamurti y la iluminación directa; Swami Vivekananda y el Vedanta; Evans-Wentz y las doctrinas tibetanas; Richard Wilhhem y la tradición taoísta; el controvertido George. I. Gurjieff; el mitólogo Joseph Campbell; el filósofo Alan Watts; la cardióloga Thérésse Brosse; los psiquiatras Stanislav Grof y Claudio Naranjo; el filósofo Ken Wilber; el antropólogo Mircea Eliade, además de la tradición sagrada como el Gilgamesh, la Bhagavad Guita, los Upanishads, el Tao, Jesús, el Sutra del corazón y un largo etc., imposible de listar aquí.

En nuestras conversaciones intercambiamos conocimientos sobre el puente Einstein-Rossen, metáfora del puente Oriente-Occidente. Y cómo importantes profesionales como Walsh (1999 a b) y Vaughan (1999) ya propugnaban el término de psicologías orientales, ampliando pedagogía en universidades californianas.

\section{Un segundo Reto: EI Proceso Oxigeme y la sabiduría intemporal}

\subsection{La importancia de la memoria en el proceso Oxigeme. Hacia una psicología del siglo XXI}

La Sombra de la memoria. Este reto implicaría una investigación en los estados expandidos de consciencia. En este sentido, en el Proceso Oxigeme hemos aprendido bastante de esa sabiduría antigua, a fin de integrarla con la ciencia moderna. El proceso terapéutico llevaría en parte activar las memorias más profundas de la genealogía para entrar en la curación y el perdón. La herencia se manifiesta, según nuestra práctica clínica e investigadora, en un complejo sindrómico emergente que se expresa en fractales, rutas disipativas, corazas y traumas. Comprendería pues una forma de entender la memoria desde los procesos nolineales que tienen en cuenta las ideas de Humberto Maturana, Francisco Varela e Ilia Prigogine (Almendro, 2002, 2013; Almendro \& Weber, 2012).

La memoria es tenida en cuenta en los textos tradicionales. Para la tradición budista Abbidharma, la consciencia registrada es la etapa final 
identificada por los textos antiguos en la que la experiencia de la consciencia se almacena en la memoria (Lancaster, 1997, 2011).

«Para que el alma se venga a unir con Dios ha de renunciar a toda posesión de la memoria [...]» (San Juan de la Cruz, 1999, Vol. 1: 332). "Cuando se ha conseguido matar la memoria - dice San Juan de la Cruz- se está en una situación que solo dista un grado de la perfección [...]» (Enomiya-Lassalle, 1982: 69). También Santa Teresa de Jesús alude al daño que hace la memoria a la hora de profundizar en la oración «[...] que le da tal guerra la memoria en imaginación [...]» (Santa Teresa de Jesús, 1979: 243). En relación con los términos técnicos budistas, «estrictamente hablando, smrti, literalmente, significa memoria, es el aspecto de enfoque de la mente, e históricamente se traduce a menudo como mindfulness» (Lutz, Dunne y Davidson, 2007: 507). Quizás el estar en paz con los ancestros, lección que el maestro curandero enseña, signifique estar en paz con la memoria.

En relación con el papel de la memoria en la práctica meditativa está ganando relevancia el papel de la Default Mode Network (DMN: red neuronal por defecto. Raichle y Snyder, 2007). Se cree que la DMN -que se activa en reposo, sin que aparentemente haya demandas que lo exijan- está relacionada con los denominados stimulus independent thoughts (SITs: pensamientos independientes del estímulo), concepto muy relacionado con el de mind wandering (mente vagabunda). Aparece sin motivo aparente una memoria autobiográfica, un self narrativo (Gallagher, 2000). Lo que tal vez tenga relación a un antes - pensamiento refractario- o a un posible después -pensamiento anticipativo- (Almendro 2009; Almendro y López-Suárez, 2016).

El proceso clínico implicaría pues en el proceso OXIGEME ${ }^{\mathrm{TM}}$ una limpieza de la herida familiar y ancestral. Curar la deliciosa programación de padres a hijos y de hijos a nietos que repiten una y otra vez los mismos modelos en un clarooscuro resistente. Por lo tanto, dar respuestas para establecer el conocimiento como una vía de curación, dar respuestas al sufrimiento, a los terribles diagnósticos y a los procesos terminales en un mundo que ni siquiera se pregunta el por qué estamos aquí. Quizás la patogenia personal y social tenga su origen en el abandono de la vida interior para ser cambiado por el dominio del mundo exterior. Y así nos van las cosas. A niveles individuales hemos de liberar y no encapotar el dolor. No cabe ya más que aceptar y comprometerse en el proceso 
terapéutico con el propio ciclo personal de vida y de actuar según el lugar que uno ocupa en el mundo. Y a partir de ahí, retroalimentar los frutos con el mundo exterior. ¿Habrá tiempo?

La disolución de esa sombra implica conocer el molde del hombre, y a partir de las teorías del caos y de las psicologías occidentales -desarrollando metodologías específicas- se produciría ese acercamiento. Recalcamos que la estructura humana se compondría de fractales (patrones corporales-emocionales-mentalesenergéticos) y traumas (heridas del pasado remoto e inmediato) que nos empujan a actuar de una forma indeseada y que no podemos controlar. Esta estructura interactúa desde el pasado sobre el presente, siguiendo las leyes del caos, a través de lo que denominamos estructuras disipativas de los personajes y de los sucesos. Aunque tienden a perpetuarse, su fin es la evolución de la persona, si se produce un proceso curativo adecuado. Sus consecuencias pueden llegar a alcanzar proyecciones sociales (Almendro 2013, Almendro y Weber, 2012; López-Suárez et al., 2017). El obstáculo es ya la oportunidad de la palanca.

\section{La meditación y el mindfulness}

He compartido con María Teresa el interés por esta vía que se remonta en ambos a los años setenta, orgullosa ella de haber estado con Tarthang Tulku; y, en mi caso, en el mundo del Zen. De las charlas dharma que nos han proporcionado en estas últimas décadas los maestros orientales hemos sabido de forma directa el profundo conocimiento que estos maestros tenían de los entresijos de la mente y del proceso intelectual que, cuando se esclaviza a la rumia, genera las locuras de nuestro tiempo. Y además enseñaban cómo encauzarla hacia el silencio. Quizás Swami Vivekananda -quien introdujo de forma espectacular la sabiduría de Oriente en el Parlamento de las Religiones en 1983- sea uno de los que concreta los pasos propios del proceso de realización. Vivekananda expone las razones y el sentido de la meditación, de su yoga. De cómo el proceso hace que se llegue a percibir la vacuidad del mundo exterior, en el que los objetos que proporcionan placer -tras la esclavización al dualismo- de inmediato proporcionan dolor; e incluso de la programación que los líderes ejercen generando servilismos en patriotismos, modas y famas. Hasta que se llega a la libertad del sabio, acceder a su propio centro divino, pratyaksha: la percepción directa (Vivekananda, 1986: 
181, 182, 183). Con ello desarrolla el arquetipo del camino presente desde los albores del espacio-tiempo y evocado por muchos maestros con sus especiales pavimentos.

La meditación, que nos enseña a entrar en la paz y a veces en la zozobra interior, proporciona entendimiento, si hay adherencia al proceso. Salir, por fin, de la máquina pensante que muchas veces se entrampa en un juego neurótico de ping/pong enrejado, que se proyecta en la conducta. Sin embargo, cuando se accede al silencio se avanza en la paz mental y poco a poco se va entrando en el silencio fértil.

Quizás por un servicio dharma, el mindfunless, fruto de desligar el proceso devocional a la meditación - palabra que por cierto Thich Naht Hanh utiliza- ha entrado de lleno en el Occidente materialista al ofrecer una terapia basada en la reducción de estrés (Kabat-Zinn, 2007). Hay contestaciones a esta proliferación del mindfulness desde muchos ángulos: devocionales, académicos de solera y desde el mundo meditativo. Son, sobre todo, críticas que se despachan sobre un cierto arribismo, ya que de forma a veces incrédula se explota el asunto macdonalizando una práctica milenaria que ha sido validada de forma eficiente y efectiva; es decir, pura evidencia práctica. La expansión es muestra de su aceptación, fruto de que hay una ciencia interior que aprueba.

Hay críticas que nosotros resolvemos en nuestra escuela tras abrir el campo para ambas líneas de meditación-mindfulness y ofrecer escaleras con peldaños a ras de tierra. Hemos comprobado que la mente errática está atrapada de forma estresante entre el pensamiento anticipativo sobre el futuro y el pensamiento refractario del pasado; y la meditación-mindfulnes trata de regular este estrés tras alcanzar el silencio mental, por el que la psicología vuelve a casa. Por ello proponemos como método científico que el modelo primera persona (meditador) sea previo a ocupar el lugar de tercera persona (observador). Además, para tratar de salir del desconocimiento de los profundos procesos cerebrales que concuerdan con los del Riba (2016). En la ya mencionada investigación, utilizando la técnica de RV (Respiración Ventral) y el enfoque neurofenomenológico, se estudian los correlatos neuroeléctricos (técnicas de EEG) de los tres estados de meditación en OXIGEME: Mente Una (MU), Mente en Silencio (MS) y Consciencia Penetrante $(\mathrm{CP})$. Los resultados muestran que en $\mathrm{CP}$ se registra mayor actividad de las ondas más rápidas en áreas parietales-occipitales (sobre todo en la frecuencia gamma) y menores en ondas más lentas (theta) en algunas áreas posteriores y en betal frontal. La mayor actividad gamma posterior indica que los estados más 
profundos van acompañados de una mejor y más integrada percepción sensorial. Por otro lado, la menor potencia en la banda theta en áreas posteriores indica una menor distracción -más presencia-, mientras que la menor actividad betal frontal indica menor actividad analítica de los contenidos de la experiencia. En resumen, en CP se da una mayor capacidad perceptiva, sin juicio y con más presencia (López-Suárez, 2016; Almendro y López-Suárez, 2016; Almendro y López-Suárez, 2017).

Y de esas charlas dharma mencionadas surge ese no pienso, luego existo. En ellas Seon Sa Nin, como otros maestros zen nos encomiaban a acceder al "mundo antes del pensamiento», aquietar la mente, las emociones y el cuerpo, para entrar en el «mundo del silencio revelador» y en las dimensiones de la Consciencia. Sabiendo que ese acceso supone rebasar la mente pensante que no cesa y que nos impide estar en la calma, cuyas consecuencias producen el estrés de la modernidad. Incluso en épocas de estudiante, en la Facultad de Psicología de la Universitat de Barcelona, comentábamos entre los interesados el enorme conocimiento que tenían estos maestros de los entresijos de la mente, de sus agitaciones, así como de la metodología que proponían para el cese de las fluctuaciones a fin de acceder al desapego frente al deseo.

El ego mental infectado de narcisismo se revuelca entre los instintos que hoy han alcanzado el poder mediático en el mecanizado mundo occidental y ya cotiza en bolsa, vendiendo un placer imposible y cuya satisfacción no implica su extinción sino su retroalimentación hacia el inframundo, en una sociedad dominada por la máquina y el IPC. Ya el viejo Freud avisaba de que la pulsión acaba bordeando al objeto.

Qué es Meditación: La naturaleza del sujeto está constituida por la misma esencia que la naturaleza del objeto; y, su fusión, a través de la meditación, es un misterio que ha de ser abierto a solas. Y correspondería a la fusión observador = observación $=$ lo observado.

En el campo de la meditación se encuentra una disciplina sobre la que compartimos con María Teresa algunas discusiones. Me refiero a la psicología transpersonal, y de la que fui un introductor en su tiempo. Un programa se quedó en el tintero de la TV2. Le hice saber que actualmente soy un crítico sobre esta disciplina por el despilfarro realizado, ya que el oportunismo y el infantilismo adornado de espiritualismo mágico, a lo que se une el olvido del puente sabiduría antigua-ciencia moderna, ha dado al traste con las exigencias de Maslow 
y Suttich, como bien explica Friedman (2000). Hay un intento-pregunta que hemos lanzado yo mismo desde Oxigeme y Douglas MacDonald desde la Universidad Merçi de Detroit, para ver si es posible la recuperación (Almendro y MacDonald (eds.) en prensa).

Y sobre meditación pasamos largos ratos hablando de maestras cercanas como Ana María Schlütter, Concha Quintana, Seon Sa Nim, Taisén Deshimaru, Nagarjuna, sobre centros de Barcelona, Madrid etc.

\section{Las Maletas de María Teresa}

María Teresa nos regala una pequeña enciclopedia vital para tiempos de estrés, para salir de la desesperación de generaciones presentes y futuras, para poder saltar ante el abismo con la esperanza puesta en el amanecer de una conciencia renovada.

La maleta de una buscadora incesante se centra en el legado de las sabidurías orientales de la antigüedad. Un libro se hace limitado, por ello María Teresa se ha afianzado de forma efectiva y ha luchado por expandir concepciones básicas, plantando semillas en el núcleo de cómo esta sabiduría realiza su puesta en escena en esta vida y en su salida personal, cuando sobreviene la muerte. Además, critica cómo los eruditos del ámbito occidental han ignorado o subestimado todas las culturas que les eran ajenas. Y en el caso de las orientales, todo su potencial civilizador, cultural, ético y sapiencial proveniente de las más grandes: Egipto, Mesopotamia, Irán, India, el budismo y China (Román, 2008).

Precisamente en este último libro nuestra profesora hace una referencia a un maestro que en el siglo XII pronostica que la humanidad ha errado su camino. La globalización hace ya que conozcamos a personas de todos los países y credos; y esto nos pone de manifiesto que la sociedad quizás marche hacia una constitución de individuos-mecano moldeados por el consumismo como religión. Si esto es así, la causa podría estar -recalcamos- en haber escogido volcarnos hacia el mundo exterior, negando nuestra interioridad y responsabilidad hacia esa consciencia punta fundamental de este escrito. Esperemos que sólo sea una vuelta más en el camino. 
Por ello necesitamos una maleta rica en seleccionar sabidurías para un buen lector que sea capaz de transformar las palabras en intuiciones, de tal forma que sean ayudas en el camino. Y por ello aparece la llamada de la verdad de la otra orilla, la percepción directa que se abre después de resolver las resistencias y poder así entrar en el misterio inexpresable. Esas resistencias que se nutren por el laberinto del hacer y deshacer lo que otros les dicen que deshagan o hagan. Y para romper este hechizo María Teresa recorre el anhelo de maleta y camino valiente, lo que le ha llevado a romper con el mundo de las pseudo-verdades que se escudan en el razonamiento negativo, en los espasmos intelectuales, egos que acumulan información en los armarios de la memoria y que filtran el mundo a través de sus condicionamientos sociales sepultados en su narcisismo o en el sometimiento al líder, eludiendo toda responsabilidad. María Teresa ofrece una información a base de ideas, herramientas útiles y valiosas, avisando de que formamos parte de un mundo fragmentario, ilusorio, durmiente, en conflicto, que pone en peligro la existencia misma de la humanidad. Por ello propone entrar en terreno extranjero que es nuestro propio universo interior para alcanzar la paz y el perdón (Román, 2011).

Los últimos intercambios con María Teresa fueron a raíz de su último libro del que realicé el prólogo. Fue una puesta a punto entre María Teresa, Agustín Pániker, editor, y yo mismo sobre un trabajo -que se notaba- era especial para su autora, quizás el presagio de un final. En el momento en que el libro salía, María Teresa nos dejaba. Entendíamos el libro como un abanico de información que reflejaba el viaje vital de una profesora de la consciencia y su legado basado en el mundo de la tradición, llamémosle sagrada, ya que se entiende como el encuentro de la puerta vital al sentido del mundo y al sufrimiento existencial, que muchas veces se esconde en el silencio. La autora plantea el nudo que implica saber cuál es la naturaleza de la realidad, para indagar en el legado de la ciencia responsable que se alinea con la vía de una nueva consciencia, y ambos anhelos confluyen en vasos comunicantes y de servicio. Y echa mano de los sueños, el despertar al sueńo del mundo, la muerte y su acercamiento, el papel del maestro y del iniciado, las escuelas de vida, la conciencia chamánica, conocimiento que al igual que en asuntos de meditación María Teresa me inundó en preguntas. Su último libro termina con un mensaje positivo e imprescindible: el amanecer de una nueva conciencia. Con una llamada urgente para la integración del saber al servicio a la humanidad y no al consumismo, y con una clave: se desarrolla en un marco académico riguroso (Román, 2017). 


\section{Y Ilegamos al Final}

No cabe más que sentir agradecimiento por el hecho de que una profesora universitaria esté en línea con muchas inquietudes internacionales que marchan hacia la integración del saber ante la incertidumbre que se avecina y la tendencia en muchos individuos de comenzar una investigación sobre lo que pasa dentro de cada ser humano.

Agradezco al corpus académico de la Facultad de Filosofía de la UNED por haber albergado a esta maravillosa persona. Sabiendo por experiencia clínica que a veces la calidad académica se esfuma porque lo que prima es la lucha por el puesto y los intereses políticos. Dicho queda que una investigación interesante no parezca demencial a primera vista. Y sí se puede investigar sobre estos legados, y para ello las neurociencias pueden ser de gran ayuda, para que los asustados reaccionarios no deroguen todo a pseudo-ciencia o a esoterismo por el supuesto de que no quepa en su cinta métrica. Claro que para ello las Facultades, y entre ellas las de Psicología, han de ser capaces de cubrir el mundo empírico, no sólo con cuestionarios sino con aparatos sofisticados que nos den información sobre la correspondencia entre los estados de consciencia y sus reflejos neuronales y corporales en general. Olvidados personajes de talla como Rof Carballo, José Luis Pinillos, Josep Lluis Barraquer Bordas, ya lo propugnaban ¿habrá esperanza? Conversando en Sacramento (California) con unos editores, su sentencia fue que España sería el último sitio al que acudirían a buscar novedades revolucionarias sobre las nuevas investigaciones acerca de la consciencia. Fue al sugerirles por mi parte algunos trabajos y me quedé estupefacto sobre sus opiniones.

Conozco personajes inquietos, pero están fuera de las Facultades, aquí no se da el caso de ofrecer el sótano de las universidades para que investiguen los locos del caos, cuando surgió esta tendencia. Simplemente se les devalúa y se les conmina a seguir lo que ya está hecho, no sea que superen a la mediocridad. En nuestras últimas publicaciones sobre consciencia y meditación, buscando bibliografía por el placer de colocar a colegas, los más citados (excepto honrosas excepciones) han sido San Juan de la Cruz y Santa Teresa de Jesús. Claro que los de Sacramento no se habían enterado de que una bilbaina llamada María Teresa Román, profesora de la Facultad de Filosofía de la UNED, superaba con creces sus expectativas.

El legado de María Teresa formará parte de la tradición si los escuchas lo saben apreciar. Es una siembra que nos guía en el camino de una nueva reorganización 
de la vida sumida en la incertidumbre y desestabilización, y por lo tanto también de coraje de una vida académica al servicio de las nuevas generaciones.

María Teresa será un ideal de orientación para abrir la puerta a la nueva Ciencia y Consciencia, aunque tengamos que caminar en este terreno movedizo que aguarda más allá del caos. Espero que cuando entregue el palmarés de sus andanzas sea bien recibida por esa Consciencia que proclama la sabiduría intemporal, y por haber salido de la mediocridad competitiva que nada aporta.

Y por supuesto María Teresa nos ha puesto cara a cara frente a nuestro inevitable ser extranjero: nuestro ser interior al que se accede a través del silencio. Por eso no pienso, luego existo.

\section{Dedicatoria}

Hola, María Teresa: decirte que me han propuesto un escrito para recordar tu legado; y, por fin, aquí lo tienes. Espero que sea de tu complacencia ya que trata de seguir la línea universal por la que se entrelazan las sabidurías intemporales de Oriente y Occidente, y la buena y nueva ciencia. De todo ello trato de dar cuenta esperando que no disparen contra el pianista. Por suerte tu Facultad de Filosofía es sensible a todo ello y se alinea con importantes universidades internacionales para dar respuestas a este mundo alocado que no cesa.

\section{Bibliografía}

Almendro, M. (2013). Chaos Psychology and Psychotherapy. Houston Texas: The writen spiral. Lantia publishing.

— (2009). «Crisis Emergente». En Almendro, M. (ed.). Krisis. Barcelona: La Llave.

- $\left({ }^{6} 1994\right)$. Psicología y psicoterapia transpersonal. Barcelona: Kairós.

- (31994). La consciencia transpersonal. Barcelona: Kairós.

Almendro, M.; López-Suárez, E. (2016). «Beyond Frontiers: Meditative Practice, Clinical Practice and Scientific Research». J Psychol Psychother 6:281.

- (2017). Más allá de las fronteras: Práctica Meditativa, Práctica Clínica e Investigación Cientifica. Infocop. 
Almendro, M.; López-Suárez, E.; Horrillo, B. (en prensa). Medicina Tradicional Indigena (MTI) en la Amazonía Peruana. Una Investigación introductoria. Mediciones empiricas sobre la complejidad de sus plantas y dietas.

Almendro, M.; Weber, D. (2012). «Dissipative processes in psychology: From the psyche to totality». International Journal of Transpersonal Studies, 31 (2), 1-22.

Almendro, M. MacDonald, D. (ed.). Transpersonal Psychology as a Science. En prensa.

Assagioli, R. (1971). Psychosyntesis. New York: Viking.

Aurobindo, S. (1997). The Complete Works. Pondicherry, India: Sri Aurobindo Ashram.

Bertalanffy, L.V. (1992, 1975). Perspectiva desde la T.G.S. Madrid: Alianza (Bertalanffy L.V. (1975). Perspectives on General System Theory - Scientific - Philosophical Studies. N.Y.: George Brazille).

Boнm, D. (1987). La Totalidad y el Orden Implicado. Barcelona: Kairós (Bohm, D. (1980). Wholeness and the Implicate Order. London/Boston: Routledge \& Kegan Paul).

(1988). Ciencia, Orden y Creatividad. Barcelona: Kairós. (Bohm D. (1988). Science, order and Creativity. London: Routledge).

Briggs, J.; Peat, F. D. (1999). Seven life lessons of chaos: Timeless wisdom from the science of change. New York: Harper Collins.

Campbell, J. (1993). El héroe de las mil caras. México: Fondo de Cultura Económica. (Campbell, J. (2008). The hero with a thousand faces. California: New World Library. Bollingen Series XVII. The Collected Works of Joseph Campbell Series).

(1991). The hero's journey: Joseph Campbell on his life and work. New York: Harper \& Row.

Cardeña, E; Lynn, S.; Krippner, S. (2000). Varietis of anomalous experiences: Examining the scientific evidences. Washingthon, DC: American Psychological Association.

Chalmers, David. J. (I999). La Mente Consciente. Barcelona. Gedisa.

Crombach, L. J. (1975). "Más allá de las dos disciplinas de la psicología científica». American Psychologist, pp. 116-127.

Davies, P. (1992). Proyecto Cósmico. Madrid: Pirámides.

(1988). The Cosmic Blueprint: New Discoveries in Nature's Creative Ability to Order the Universe. New York: Simon and Schuster.

Davies, P.; Gregersen, N. H. (eds.) (2010). Information and the Nature of Reality: From Physics to Metaphysics. Cambridge: Cambridge University Press.

Dawkins, R. (1976). The Selfish Gene. New York: Oxford University Press.

D’Espagnat, B. (1995). Veiled Reality. Massachusetts: Addison Wesley. 
Descartes, R. (1993). El Discurso del Método / Meditaciones Metafísicas. Ed. de M. García Morente. Madrid: Austral (Espasa-Calpe).

Dodds, E. R. (1980). Los griegos y lo irracional. Madrid: Alianza. (Dodds, E. (1951). The Greeks and the Irrational. The regents of the University of California).

Einstein, A. (1980). Mis ideas y opiniones. Barcelona: Antoni Bosch (Einstein, A. (1960/1954). Ideas and Opinions. New York: Crown Publishers).

Eliade, M. (1994). El chamanismo y las técnicas arcaicas del éxtasis. México D. F.: Fondo de Cultura Económica (Eliade, M. (1951). Shamanism: Archaic Techniques of Ecstasy. Princeton: University Press).

Enomilla-Lassalle, E. (1982/1981). ¿A dónde va el hombre? Santander: Sal Térrea (Enomiya-Lasalle, E. (1981). Wohin geht der Mensch? Zürich-Köln: Benziger Vg.).

Evans-Wentz, W. Y. (1971). Yoga tibetano y doctrinas secretas. Buenos Aires: Kier.

Feyerabend, P. (1975). Against Method. London: Verso.

Friedman, H. (2000). "Toward developing transpersonal psychology as a scientific field». Paper presented at Old Saybrook 2 Conference. State University of West Georgia, Carrolton, Georgia. Retrieved from http://skaggsisland.org/humanistic/friedman. html.

Gallagher, S. (2000). «Philosophical conceptions of the self: Implications for cognitive science». Trends Cogn Sci 4, pp. 14-21.

Gebser, J. (2011). Origen y presente. Memoria Mundi. Traducción de José Rafael Hernández Arias. Vilaür: Ediciones Atalanta (Gebser, J. (1985/1949). The Ever-Present Origin. Noel Barstad con Algis Mickunas Translators from German language. Athens: Ohio University Press).

Gilgamesh (2006). J. Silva (ED.). Barcelona: Kairós. (Gilgamesh The Epic of (1999). Translation by Andrew George]. London: Penguin Books).

Gödel, Kurt (1986/1931). Collected works. On formally undecidable propositions of Principia Mathematica and related systems. Oxford: Oxford University Press.

Heisenberg, W. (1949). The Physical Principles of the Quantum Theory. (Trans. Eckart, C. and F.C. Hoyt, F.C.) USA: Dover Publications INC.

Hunt, H. (2007). «Dark nights of the soul: Phenomenology and neurocognition of spiritual suffering in mysticism and psychosis». Review of General Psychology, 2007, 11 (3), 209-234.

Hunt, H. (2006). "The truth value of mystical experience». Journal of Consciousness Studies, 12, 12, 26-45.

John Roll I.; Lother Konrad, S. (1989). Historia de la Biología. Barcelona: Labor.

James W. (1956). «The dilemma of determinism», The will to believe. New York: Dover. 
James, W. (2002/1902). Las variedades de la experiencia religiosa: estudio de la naturaleza humana. Barcelona: Península (James, W. (1902). The varieties of religious experience: a study in the human nature. N.Y.: Longmans Green).

Juan-Espinosa, M. D. (1997). Geografia de la inteligencia humana. Madrid: Pirámides.

Jung, C. G. (2016). Obras Completas. Madrid: Trotta (Jung, C.G. (1977). Collected Works. Edited and translated by Gerhard Adler and R.F.C. Hull. Princeton University Press).

Kabat-Zinn (2007). La práctica de la atención plena. Barcelona: Kairós.

Krippner, S; Achterberg, J. (2014/2000). Anomalous Healing Experiences. In Cardeña, E; Lynn, S; \& Krippner, S. Varieties of anomalous experiences: Examining the scientific evidences. Washingthon, DC: American Psychological Association.

Kunn, Tн. S. (1975/1962). La Estructura de las Revoluciones Cientificas. México. ( Kuhn, Th. S. (1962). The Structures of Scientific Revolutions. Usa: University of Chicago).

Laín Entralgo, P. (1999). Qué es el Hombre. Oviedo: Nobel.

LANCASTER, L. B. (2011). «The cognitive neuroscience of consciousness, mysticism and Psi». International Journal of Transpersonal Studies 30, pp. 11-22.

Laughin, Ch. D; Rock, A. J. (2013). «Neurophenomenology: Enhancing the experimental and cross-cultural study of brain and experience». The Wiley-Blackwell Handbook of Transpersonal Psychology. Friedman, H; Hartelius, G. (eds.). Chichester: Wiley Blackwell.

Laughlin Ch. D. Jr; McManus, J.; D’Aquili, E. G. (1990). Brain, Symbol \& Experience. Toward a Neurophenomenology of Human Consciousness. Boston: New Science Library.

López-SuÁrez, E. (2016). Estados de consciencia durante la práctica meditativa: un estudio neurofenomenológico. Directores: Rafael Jódar Anchía. Lucí Halty Barritieta. Madrid: Universidad Pontificia Comillas de Madrid. Facultad de Ciencias Humanas y Sociales. Departamento de Psicología. (López-Suárez, E. (2016). Consciousness states during meditative practice: a neurophenomenological study /Estados de consciencia durante la práctica meditativa: un estudio neurofenomenológico (Doctoral Dissertation, Universidad Pontificia Comillas de Madrid, Spain). Transition and Inestabilities. N.Y. Edit. T Riste. Plenun, p. 259.

Lopez-SuÁrez, E.; Jodar, R.; MacDonald, D. A. (2017). «Psychometric properties of a Spanish adaptation of the Expressions of Spirituality Inventory-Revised». International Journal of Transpersonal Studies. 
López-SuÁrez, E.; Malkemus, S.; Redondo, M.; Hernando, R.; Rodríguez, J. and Edward J. Dale (2017). "Book Review: Chaos Psychology and Psychotherapy». J. Psychol Psychotherapy $7 / 1$.

Lorenz, E. N. (1995). La esencia del caos. Barcelona: Debate.

Lutz, A.; Dunne, J. D.; Davidson, R. J. (2007). «Meditation and the neuroscience of consciousness: An introduction». En: Cambridge Handbook of Consciousness. Cambridge: Cambridge University Press.

MacDonald, D. (2000). «Spirituality: Description, measurement, and relation to the five factor model of personality». Journal of Personality 68 (1), pp. 153-197. (Spanish adaptation by López-Suárez, E.; Jódar, R.; MacDonald, D.A. (2014). Psychometric properties of a Spanish adaptation of the "Expressions of Spirituality InventoryRevised"(ESI-R).

Mandelbrot, B. (1988). Los objetos fractales. Barcelona: Tusquets.

Mandell, A. J. (1985). «From Molecular Biological Simplification to More Realistic Central Nervous System Dynamics: An Opinion». En: Psychiatric: psychobiological Foundation of Clinical Psychiatry 3/2.

Maturana, H.; Varela, F. J. (1984). El árbol del conocimiento. Madrid: Editorial Debate (Maturana, H.; Varela, F. J. (1997). The Tree of Knowledge: The Biological Roots of Human Understanding. Boston: Shambhala).

Monserrat, J. (1987). Epistemología evolutiva y teoría de la ciencia. Madrid: Universidad Pontificia de Comillas.

(1995a). «¿Está realmente el mundo en mi cabeza? A propósito de J.J. Gibson y D. Marr». En: Pensamiento 200 (51), pp. 177-213.

(1995b). «Lectura epistemológica de la teoría unificada de la cognición en Allen Newell». En: Pensamiento 199 (51), pp. 3-4.

Morin, E. (2011). La Voie. Pour l'avenir de l'humanité. Paris: Fayar.

(1974). El paradigma perdido: el paraíso olvidado. Barcelona: Kairós.

Newton, I. (1992). El sistema del mundo. Madrid: Alianza.

(1994). Principia. Madrid: Tecnos.

Ortega y Gasset, J. (1997a). Obras completas, Lección I. Madrid: Alianza.

(1997b). Obras completas, Lección III. Madrid: Alianza.

(1983/1997c d). Obras completas, Lección IV. Madrid: Alianza.

PÁniker, S. (2016). Asimetrías. Barcelona: Kairós.

(1989). Aproximación al Origen. Barcelona: Kairós.

PeAt, D. (1988). Sincronicidad. Barcelona: Kairós. 
Pinillos, J. L. (1999). El corazón del laberinto. Madrid. Espasa Calpe.

Popper, K. (1994). El universo abierto y sus enemigos. Madrid: Tecnos.

Platón (1954). Cartas. Edición de M. Toranzo. Madrid. Instituto de Estudios Políticos.

Prieto, J. M. (2007). «Psicología de la meditación, la psique de vuelta a casa». InfoCopOnline: Revista de Psicologia, 33, Disponible en http://www.infocop.es/view_article.asp?id=1456 .

Prigogine, I. (1984). Order out of Chaos: Man's New Dialogue with Nature. New York: Bantam.

Prigogine I.; Stengers, I. (1994). La Nueva Alianza. Madrid: Alianza.

Raichle, M. E.; SNyder, A. Z. (2007). "A default mode of brain function: a brief history of an evolving idea». Neuroimage 37, pp. 1083-1090.

Riba, J. (2016). Ayahuasca y Neurociencia. Grupo de Investigación en Neuropsicofarmacología Humana Instituto de Investigaciones Biomédicas Sant Pau. Hospital de Sant Pau, Barcelona.

Rock, J.; Krippner, S. (2011). Demystifying Shamans and their World. Charlottesville: Imprint Academic.

Rof Carballo, J. (1990a). Entre el silencio y la palabra. Madrid: Espasa.

(1990b). Duendes del prado. Madrid. Espasa.

(1988). Violencia y ternura. Madrid: Espasa.

(1970). Rebelión y futuro. Madrid: Taurus.

Román, M. T. (22008). Sabidurías orientales de la antigüedad. Madrid: Alianza.

(2011). La maleta del buscador. Madrid: Miraguano.

(2017). La exploración de la consciencia. En Oriente y Occidente. Barcelona: Kairós.

Rubia-VILA, F. J. (2006). ¿Qué sabes tú de tu cerebro? Madrid: Temas de Hoy.

San Juan de la Cruz (1999). Obras Completas. Madrid: Alianza.

Santa Teresa de Jesús (1991). Camino de perfección. Madrid: Espasa.

(1981). Las moradas. Madrid: Clásicos Frailes.

(1979). Vida. Madrid: Cátedra.

SCHröndinger, E. (1998). Ciencia y Humanismo. Barcelona. Tusquets.

(1999). Mente y Materia. Barcelona. Tusquets.

Sheldrake, R. (1989). Una Nueva Ciencia de la Vida. Barcelona: Kairós.

Skinner, B. F. (1987). Walden Dos. México D.F.: Roca. 
(1971). Beyond Freedom and Dignity. New York: Alfred Knopf.

Spencer, H. (1855). The Principles of Psychology. New York: Appleton.

Unamuno, M. DE (1976). Del sentimiento trágico de la vida. Madrid: Espasa.

Upanishads (2001). C. Martín (ed.). Madrid: Trotta.

VArela, F. (1990). Conocer. Barcelona: Gedisa.

(1988). Cognitive science: A Cartography of Current Ideas (Varela, F. (1989). Connaître Les sciences cognitives: Tendances et perspectives. Paris: Editions du Seuil.

Varela, F.; Thomson, E.; Rosch, E. (1992). De Cuerpo Presente. Barcelona: Gedisa. (Varela, F.; Thomson, E.; Rosch, E. (1991). The Embodied Mind. Cognitive Science and Human Experiences. Cambridge, Massachusetts: Massachusetts Institute).

Vaughan, F. (21999). "Cuestiones espirituales en psicoterapia». En: M. Almendro (ed.). La consciencia transpersonal. Barcelona: Kairós.

Viverananda, S. (1990). Vedanta. Voice of Freedom. Sant Louis: Vedanta Society of St. Louis.

Walsh, R.N. (2007). The Word of Shamanism. New Views of an Ancient Tradition. Woodbury, Minessota: Llewellyn Publications.

(1999a). «La búsqueda de la síntesis». En: M. Almendro (ed.). La consciencia transpersonal. Barcelona: Kairós.

(1999b). «Disciplina de consciencia y ciencias de la conducta. Cuestiones comparativas y valoración». En: M. Almendro (ed.). La consciencia transpersonal. Barcelona: Kairós.

Walsh, R. N.; Vaughan, F. (1993). Más allá del ego. Barcelona: Kairós.

Wilber, K. (1999). Psicología Integral. Barcelona: Kairós (Wilber, K. (1999). Integral Psychology. Boston: Shambala).

Recibido: $16 / 07 / 2018$

Aceptado: 3/11/2018

Este trabajo se encuentra bajo una licencia de Creative Commons ReconocimientoNoComercial-SinObraDerivada 4.0 